\title{
Poly(o-arylene)s from [2.2.1]Oxabicyclic Alkenes as Monomers
}

Synthesis of

Materials and

Unnatural Products

\section{Key words}

poly(o-arylene)s

chain-growth polymerization

palladium
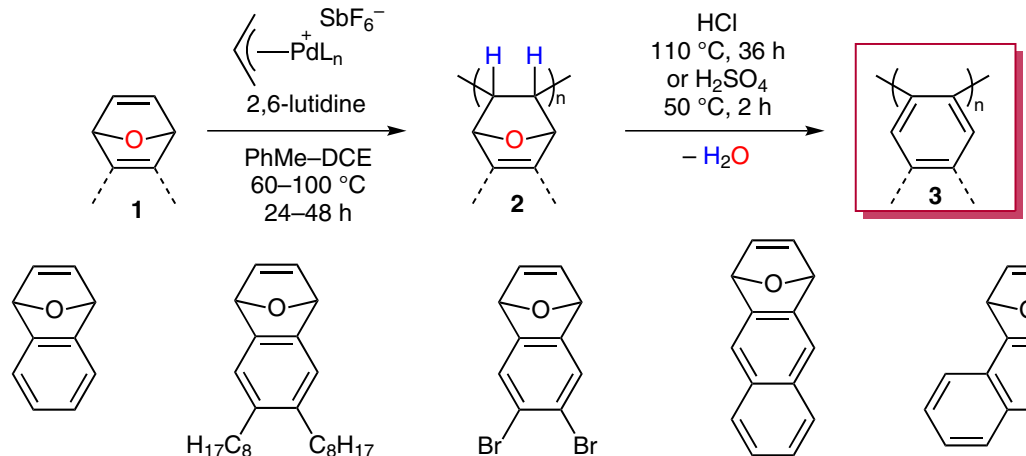

$1 \mathrm{~b}$

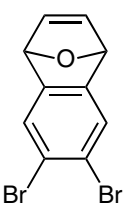

$1 c$

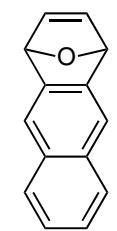

1d

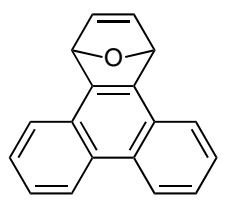

$1 e$

Plausible mechanism of the polymerization:

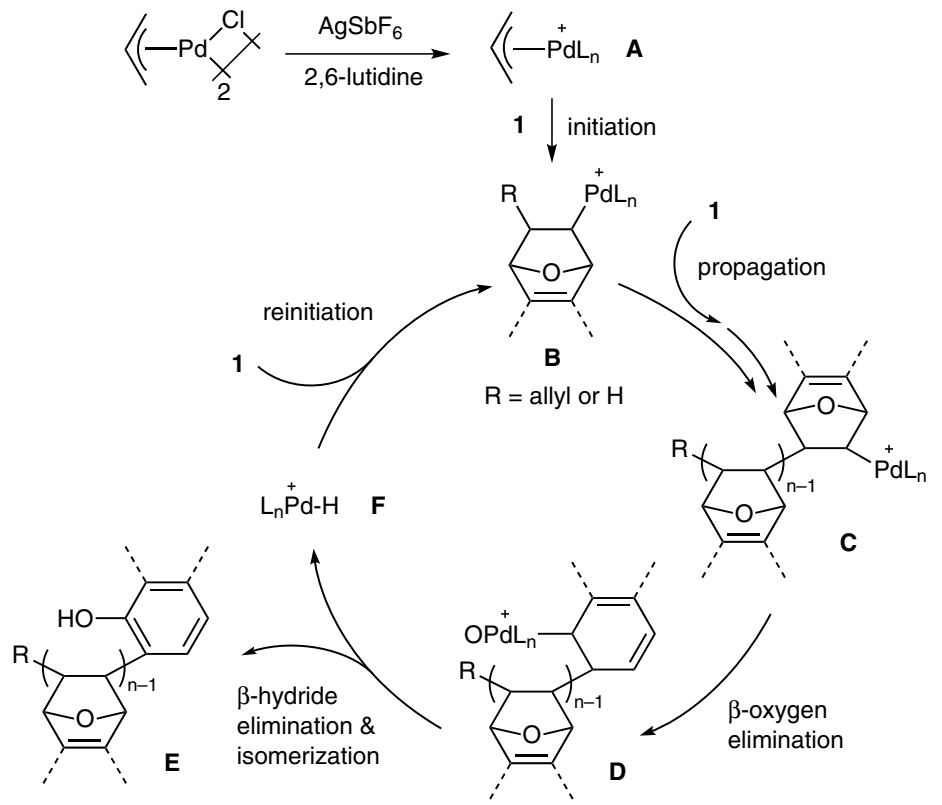

Significance: The instability of aryne has prevented its polymerization to form poly(o-arylene)s. Only few examples of oligomeric 0 -arylenes through iterative coupling reactions are reported. Ito, Takahashi, and Nozaki report the synthesis of poly(o-arylene)s via polymerization of [2.2.1]oxabicyclic alkenes, followed by acid-catalyzed dehydration.
Comment: In this chain-growth polymerization, the co-solvent and the additive 2,6-lutidine play key roles. Toluene may stabilize the cationic palladium catalyst species and may hinder $\beta$-oxygen elimination (the termination step). Dichloroethane (DCE) solubilizes the palladium catalyst in toluene. 2,6-Lutidine produces polymer 2 with high yields and a low polydispersity index.

SYNFACTS Contributors: Timothy M. Swager, Byungjin Koo Dol: 10.1055/s-0034-1378477; Reg-No.: S06914SF 